\title{
Characteristics of Epilepsy in Children with Cerebral Palsy
}

\author{
Denis Fiolita ", I Gusti Ngurah Made Suwarba, Dewi Sutriani Mahalini \\ Department of Child Health, Medical Faculty of Udayana University, Sanglah Hospital, Denpasar, Indonesia
}

Email address:

denismeregawa@gmail.com (D. Fiolita)

${ }^{*}$ Corresponding author

\section{To cite this article:}

Denis Fiolita, I Gusti Ngurah Made Suwarba, Dewi Sutriani Mahalini. Characteristics of Epilepsy in Children with Cerebral Palsy. Clinical Neurology and Neuroscience. Vol. 4, No. 2, 2020, pp. 29-32. doi: 10.11648/j.cnn.20200402.12

Received: May 10, 2020; Accepted: May 27, 2020; Published: June 4, 2020

\begin{abstract}
Cerebral palsy is a disorder of movement and posture due to disruption of the immature motoric cells in central nervous systems. It is characterized by various neurological abnormalities, one of them is epilepsy. Epilepsy is difficult to control, as it is able to aggravate motor disorders and disrupt cognitive function, ultimately worsening the long-term outcome. This research aims to determine the characteristics of epilepsy in children with cerebral palsy. A cross-sectional study was done based on medical records data Pediatric Outpatient Department and Medical Rehabilitation Installation Sanglah Hospital from January 2016 until June 2018. Eighty-four samples were included. Most of the samples were female (53.6\%) with mean of age was 64 months and onset of epilepsy was 21 months. Regarding to nutritional status, most of them with undernutrition (44\%). Based on birth history, $66.7 \%$ of them was born by spontaneous delivery, $34.5 \%$ with asphyxia and $82.1 \%$ were normal birth weight. Generalized seizure was the most common type of seizure (81\%). Most types of cerebral palsy were spastic type (94\%). History of seizures at $<1$ year of age was $63.1 \%$. History of central nervous system infection was $15.5 \%$. The most brain abnormalities was microcephaly (34.5\%). Abnormal EEG results were about $91.7 \%$, with family history of seizures was $1.2 \%$. Frequency of polytherapy with anti-epileptic drugs was $69 \%$. The most common type of cerebral palsy in this research was spastic type. Generalized seizure was the most common type of seizure in epilepsy children with cerebral palsy. Most of them have abnormal EEG results and need more than one anti-epileptic therapy.
\end{abstract}

Keywords: Cerebral palsy, Characteristic, Epilepsy

\section{Backgrounds}

Cerebral palsy is a disorder of movement and posture due to disruption of the immature motoric cells in central nervous systems that has not yet completed its growth. The diagnosis of cerebral palsy based on four of the six Levine criteria including Posturing/abnormal movement, Oropharyngeal problem, Strabismus, Tone, Evolution of maldevelopment, Reflexes [1]. The incidence of cerebral palsy varies between 1.8 to 2.3 out of 1000 live births [2]. Various prenatal, perinatal and postnatal factors can causes cerebral palsy. The most common causes are history of hypoxia, congenital brain structural abnormalities and infections [3]. There are four types of cerebral palsy, namely spastic, atonic, ataxic and mixed with the most cases are spastic types (88\%) [4]. Cerebral palsy is characterized by various neurological abnormalities which one of them is epilepsy [5]. Epilepsy is a brain disease defined in one of the following 3 conditions such as at least two seizures without provocation that occur $>24$ hours apart, one seizure without provocation and have the same risk of recurrence of seizures in the future (at least $60 \%$ ) after experience two seizures that can occur over the next 10 years, the diagnosis of epilepsy syndrome. The incidence in children is higher than adults and often begins at the infancy. The incidence of epilepsy in children in developing countries ranges from 40 cases per 100,000 children per year [6]. In Indonesia there are at least 700,000-1,400,000 cases of epilepsy with an increase of 70,000 new cases each year and an estimated $40-50 \%$ occur in children. The diagnosis of epilepsy is a clinical diagnosis that is mainly enforced on the basis of history and neurological examination [7]. Clinical manifestations of epilepsy are caused by lesions in the underlying cerebral cortex. Lesions in the brain generally exist several months or years before the first symptoms of epilepsy appear, such as perinatal hypoxia or intracerebral hemorrhage, however generally the etiology of epilepsy is not clearly known. Structural abnormalities that can cause epilepsy 
include cerebral palsy [6].

Epilepsy in cerebral palsy children is difficult to control and can aggravate motor disorders and cognitive function, worsening the long-term outcomes. Several studies have linked the incidence of epilepsy in children with cerebral palsy, where the prevalence rates still vary. Research on epilepsy in cerebral palsy children carried out by Bruck et al in 2001 found that the prevalence rate of $89.9 \%$ was different from the study conducted by Salam et al in 2016 where the prevalence rate was $58.8 \%$ however similar studies had not been conducted in Sanglah Hospital $[5,8]$. Based on the description, a study was conducted on the characteristics of epilepsy in cerebral palsy children at Sanglah Hospital. This study aims to determine the characteristics of epilepsy in children with cerebral palsy.

\section{Methods}

A cross-sectional study was done based on medical records data Pediatric Outpatient Department and Medical Rehabilitation Installation Sanglah Hospital from January 2016 until June 2018. The target population was epilepsy children with cerebral palsy in Sanglah Hospital. Affordable population was epileptic children with cerebral palsy in Sanglah Hospital in January 2016 to June 2018. Subjects were determined by consecutive sampling. The subjects of this study were part of the affordable population that met the inclusion criteria, namely epilepsy in children with cerebral palsy. Patients with genetic disorders, congenital metabolic abnormalities and incomplete data were excluded from the study.

The sample size was calculated using a descriptive study formula, with the prevalence of epilepsy in children with cerebral palsy was $50.8 \%$, the determination of accuracy was $10 \%$, and $\mathrm{Z} \alpha$ was 1.96 , and a minimum sample was 68 subjects.

The assessment and ethics feasibility information of this study was given by the Research Ethics Commission of the Faculty of Medicine, Udayana University, Sanglah Hospital, Denpasar (0041/UN. 02.1/KEP/2018).

Operational definitions of variables were as follows: age is the chronological age stated in months. Gender is the appearance of a phenotype that is divided into male and female. Nutritional status was assessed based on body weight according to body length or height and nutritional status determined using the cerebral palsy curve. Epilepsy is a brain disease that is defined as one of the following three conditions: 1). At least experience two seizures without provocation (or reflex) that occurs separately $>24$ hours, 2). One seizure without provocation (or reflex) and has the same risk of recurrence of seizures in the future (at least $60 \%$ ) after experiencing two seizures that can occur for the next 10 years, 3 ). The diagnosis of epilepsy syndrome in which epilepsy is considered manageable for individuals who have epilepsy syndrome depends on age but has now exceeded the applicable age or individuals who remain seizure free for the past 10 years, without seizure drugs over the past five years, diagnosis of epilepsy is confirmed by the doctors and data were obtained from medical records. Seizure types based on ILAE 2017 are divided into three types including focal, general and unknown. The onset of epilepsy is age when the child is first diagnosed with epilepsy. A history of seizures in the family is a history of seizures in relatives with offspring relationships. Cerebral palsy is a disorder of movement and posture due to disruption of the immature motoric cells in central nervous systems that has not yet completed it's growth, the diagnosis is based on four of six Levine criteria including Posturing/ abnormal movement, Oropharyngeal problem, Strabismus, Tone, Evolution of maldevelopment, Reflexes and data obtained from medical records. Cerebral palsy types is divided into four types including spastic, dyskinetic, ataxic and mixed. Electroencephalography (EEG) is a standard investigation of 30 minutes of brain activity recording consisting of sleep and wake up recordings without using pre-medication drugs.

All data were analyzed descriptively using computer. Data with numerical and ordinal scales were expressed in frequency distribution and percentage then presented in the form of tables and narratives.

\section{Results}

During the study period conducted from January 2016 to June 2018 at the Pediatric Outpatient Department and Medical Rehabilitation Installation at Sanglah Hospital, there were 3911 of epilepsy patients. About 206 patients with cerebral palsy. The number of epilepsy patients with cerebral palsy during the study period were 84 patients $(40.7 \%)$.

The mean age was 64 months, with male 45 subjects (53.6\%) and 39 female subjects (46.6\%). Majority of the subjects were undernutrition $(44 \%)$ and 10 subjects $(11.9 \%)$ were severe malnutrition. Based on birth history, 56 subjects $(66.7 \%)$ with spontaneous delivery, 20 subjects $(23.8 \%)$ with cesarean section, 6 subjects $(7.1 \%)$ with vacuum assisted delivery and 2 subjects $(2.4 \%)$ with forceps assisted delivery. There was 29 subjects experiencing asphyxia (34.5\%) on delivery. Based on birth weight, $82.1 \%$ subjects had normal birth weight, $13.1 \%$ subjects with low birth weight (LBW), 3.6\% subjects very low birth weight (VLBW) and 1.2\% subjects extreme low birth weight (ELBW).

Generalized seizure was the most common type of seizures $(81 \%)$. The history of central nervous system (CNS) infection was 13 subjects $(15.5 \%)$. Abnormal EEG result found on 77 subjects (91.7\%). Epilepsy treatment in cerebral palsy children with polytherapy anti-epileptic drug (AED) was in 58 subjects (69\%) (Table 1). Most types of cerebral palsy were spastic type 79 subjects (94\%) (Table 2).

Table 1. Characteristics of epilepsy.

\begin{tabular}{ll}
\hline Characteristics & $\mathbf{n = 8 4}$ \\
\hline Onset, average (SB), months & $21,81(30,89)$ \\
Seizure type, n (\%) & \\
Focal & $8(9,5)$ \\
Generalized & $68(81)$ \\
Unknown & $8(9,5)$ \\
History of seizures at under 1 year of age, n $(\%)$ & $53(63,1)$ \\
History of CNS infection, n (\%) & $13(15,5)$ \\
Family history of epilepsy, n (\%) & $1(1,2)$ \\
\hline
\end{tabular}




\begin{tabular}{ll}
\hline Characteristics & $\mathbf{n}=\mathbf{8 4}$ \\
\hline Brain abnormalities, $\mathrm{n}(\%)$ & \\
Microcephaly & $29(34,5)$ \\
Hydrocephalus & $5(6)$ \\
Hypoplasia of the corpus callosum & $1(1,2)$ \\
Cerebral hemorrhage & $2(2,4)$ \\
Hemimegaencephaly & $1(1,2)$ \\
Brain atrophy & $1(1,2)$ \\
EEG examination, abnormal, n (\%) & $77(91,7)$ \\
Therapy, polytherapy, $\mathrm{n}(\%)$ & $58(69)$ \\
\hline
\end{tabular}

Table 2. Characteristics of cerebral palsy.

\begin{tabular}{ll}
\hline Characteristics & $\mathbf{n = 8 4}$ \\
\hline Cerebral palsy type, $\mathrm{n}(\%)$ & \\
Spastic & $79(94)$ \\
Athetoid & $4(4,8)$ \\
Flaccid & $1(1,2)$ \\
\hline
\end{tabular}

\section{Discussion}

Cerebral palsy is a disorder of movement and posture due to disruption of the immature motoric cells in central nervous systems that has not yet completed its growth. The diagnosis of cerebral palsy based on four of the six Levine criteria including Posturing/abnormal movement, Oropharyngeal problem, Strabismus, Tone, Evolution of maldevelopment, Reflexes [1]. Cerebral palsy is characterized by various neurological abnormalities, one of which is epilepsy [5].

This study found the incidence of epilepsy was greater in male $53.6 \%$, this result was according to a study conducted by Gurkan et al (2018) which found that male had more epilepsy in children with cerebral palsy as much as $58 \%$ [1].

Most children with cerebral palsy experienced malnutrition and growth disorders. This is caused by nutritional and non-nutritional factors. Nutritional factors such as decreased food intake due to oromotor disorders, increased use and loss of calories. Non-nutritional factors such as age, genetics, physical activity related to neurological conditions (decreased mechanical stress to long bones), hormonal [9]. Nutritional status mostly in this study was $44 \%$ undernutrition and $11.9 \%$ severe malnutrition based on curves specifically for cerebral palsy this is in accordance with a study conducted by Aroujo et al (2013) which found the incidence of malnutrition in children with cerebral palsy as much as 56\% [10]. Research conducted by Aydin (2018) found different results in $91.3 \%$ of children experiencing malnutrition, this difference was due to the study of assessing nutritional status in children with cerebral palsy using growth curves for the general population [11].

Factors that can cause cerebral palsy are prenatal, intranatal and postnatal factors resulting in damage to the brain. Lesions in the brain generally exist several months or years before the first symptoms of epilepsy appear, but generally the etiology of epilepsy is not clearly known. This study found that $23.8 \%$ of subjects born with sectio caesarean delivery, $7.1 \%$ with vacuum assisted delivery and $2.4 \%$ with forceps assisted delivery. Research conducted by Rahmat et al (2010) found different results where as many as $17.4 \%$ of epilepsy in children with cerebral palsy were born with device assisted delivery, this difference was due to the study not clearly describing the device used in labor [12]. Asphyxia is a condition for decreased oxygen levels in the brain that cause brain damage which increases the risk of cerebral palsy and seizures. The history of asphyxia in this study was $34.5 \%$, this was not much different from the study of Sellier et al (2012) who had a history of $54.6 \%$ asphyxia in epileptic children with cerebral palsy [13]. The difference was due to the smaller number of samples in this study. Most children born with low birth weight were preterm, which is associated with sub optimal fetal brain development which will increase the risk of cerebral palsy and seizures. This study found that $13.1 \%$ of subjects was LBW, 3.6\% was VLBW and $12.1 \%$ was ELBW, this result was different from the research conducted by Sellier et al (2012) who found that history of LBW in $29.8 \%$ subjects and VLBW in $24.3 \%$ subjects [13]. This difference was due to the greater number of subjects in the study.

This study found spastic type cerebral palsy in $94 \%$ of subjects, this result was not much different from the study conducted by Salam et al (2016) which found 85.4\% of children with spastic type cerebral palsy [5]. Location and extent of brain damage in cerebral palsy determine clinical manifestations epilepsy. This study found general seizure type in $81 \%$ of subjects, this result is in accordance to a study conducted by Wibowo et al (2012) that found generalized seizures in cerebral palsy children as much as $81.4 \%$ [14].

History of seizures under the age of 1 year is often associated with epilepsy in the future, this is because in this age range the brain is still in the process of development so that any disturbances that occur will cause brain damage. This study found $63.1 \%$ of the subjects had history of seizures under 1 year of age, this result is in accordance to a study conducted by Gururaj et al (2003) which found $78.6 \%$ of epileptic children with cerebral palsy had a history of seizures under the age of 1 year [15]. A study conducted by Wibowo et al (2012) found different results in which $40.2 \%$ of children had a history of seizures at the age of under 1 year, this difference was due to the smaller number of research subjects [14]. The history of seizures in families in patients with cerebral palsy would increase risk of epilepsy. This study found $1.2 \%$ of subjects had history of seizures in the family, this result is in accordance to a study conducted by Wibowo et al (2012) who found 3.2\% had a history of seizures in the family [14]. Research conducted by Bruck et al (2001) found different result which $29 \%$ of children had a history of seizures in the family, the difference was due to incomplete information in the medical record and parents did not know the history of seizures in the family [8].

Any changes in the brain can be a risk factor for epilepsy. Abnormalities in the head circumference are the most common clinical manifestations found in epileptic children with cerebral palsy. This study found that some children had brain abnormalities such as microcephaly $34.5 \%$, hydrocephalus $6 \%$, hypoplasia of the corpus callosum $1.2 \%$, cerebral hemorrhage $2.4 \%$, hemimegaencephaly $1.2 \%$ and brain atrophy $1.2 \%$, these results was smaller than the study conducted by Gurkan et al. (2018) which found $68.6 \%$ of children with microcephaly and Sellier et al. (2012) found $52.3 \%$ of epileptic children with cerebral palsy had abnormalities in the brain $[1,13]$. The 
difference between the results, may be caused the number of subjects in this study was smaller. Cerebral palsy is a complication of CNS infection which increases the risk of epilepsy. This study found $15.5 \%$ of children had a history of CNS infection, this result was smaller when compared to a study conducted by Wibowo et al (2012) which found $75.6 \%$ of epileptic children with cerebral palsy had a history of CNS infection [14]. The difference was due to data history of CNS infection in medical records is incomplete.

The diagnosis of epilepsy is based on clinical symptoms. Disorders of brain function are not always seen in EEG recordings. Abnormal EEG images are not a risk factor in the development of epilepsy in children with cerebral palsy. EEG images interpreted as follows normal (normal basic rhythm waves and no epileptiform waves), abnormal I (abnormal base rhythm waves and no epileptiform waves), abnormal II (normal base rhythm waves and epileptiform waves), abnormal III (basic rhythm waves are not normal and there are epileptiform waves). This study found that $91.7 \%$ children with abnormal EEG result, accordance with the research conducted by Rahmat et al (2010) who found 92.8\% abnormal EEG results in epileptic children with cerebral palsy [12].

The administration of antiepileptic drugs in cerebral palsy children aims to prevent subsequent seizures, both in reducing the frequency or severity of seizures. Treatment of epilepsy is a long-term treatment, administration must consider several aspects, including risk, benefits and acceptability. The problem of epilepsy in children with cerebral palsy is generally difficult to control with an antiepileptic drug which is associated with brain damage. This study found that $69 \%$ of children need more than one AED, the results were in accordance with a study conducted by Gururaj et al (2003) which found $66.1 \%$ of epileptic children with cerebral palsy received polytherapy [15].

\section{Conclusions and Suggestions}

The most common type of cerebral palsy in this research was spastic type. Generalized seizure was the most common type of seizure in epilepsy children with cerebral palsy. Most of them have abnormal EEG results and need more than one AED.

This research was a descriptive study based on medical record data, so there were many shortcomings and weaknesses, it is recommended to conduct prospective research to obtain more precise data.

\section{Disclosure}

The authors hereby declare no personal or professional conflicts of interest regarding any aspect of this study.

\section{Acknowledgements}

None declared.

\section{References}

[1] Gurkan F, Gokben S, Serin HM, Yilmaz S, Aktan G, Tekgul H. Determining Risk Factors of Epilepsy in Children with Cerebral Palsy: a retrospective study. The Journal of Pediatric Research. Vol. 5, No. 2, 2018, pp. 76-81.

[2] Mwesige AK, Andrews C, Peterson F, Mangen FW, Eliasson AC, Forssberg H. Prevalence of Cerebral Palsy in Uganda: a population based study. The Lancet Global Health. Vol. 5, No. 2, 2017, pp. 1-7.

[3] Bearden DR, Monokwane B, Khurana E, Baier J, Baranov E, Westmoreland K, dkk. Pediatric Cerebral Palsy in Botswana: etiology, outcomes and comorbidities. Pediatric Neurology. Vol. 59, 2016, pp. 1-16.

[4] Reddy B, Ashok, Eluzai Z. A Study of Clinical Spectrum and Risk Factors of Cerebral Palsy in Children. IOSR Journal of Dental and Medicine Science. Vol. 17, No. 1, 2018, pp. 49-52.

[5] Salam OA, Esmael A, El-Sherif M. Epilepsy among Cerebral Palsy Children: clinical predictors and frequency. International Neuropsychiatric Disease Journal. Vol. 6, No. 2, 2016, pp. 1-8.

[6] Mangunatmadja, Handryastuti S, Soetomenggolo HAF, Soebadi A, Nurmalia LD. Epilepsi pada anak. in: Mangunatmadja I, Handryastuti S, Risan NA, editors. Buku edukasi dokter. $1^{\text {st }}$ edition. Jakarta. IDAI, 2016, pp. 1-66.

[7] Suwarba IGNM. Insiden dan karakteristik klinis epilepsi pada anak. Sari Pediatri. Vo. 13, No. 2, 2011, pp. 123-8.

[8] Bruck I, Antoniuk A, Spessato A, dkk. Epilepsy in Children with Cerebral Palsy. Arquivos de Neuro Psiquiatria. Vo. 59, No. 1, 2001, pp. 35-9.

[9] Rempel G. The Importance of Good Nutrition in Children with Cerebral Palsy. Physical Medicine Rehabilitation Clinics of North America. Vol. 26, No. 1, 2015, pp. 39-56.

[10] Aroujo LA, Silva LR. Antrhropometric Assessment of Patients with Cerebral Palsy: which curves are more appropriate? Jornal de Pediatria. Vol. 89, No. 3, 2013, pp. 307-14.

[11] Aydin K. A Multicenter Cross-sectional Study to Evaluate The Clinical Characteristic and Nutritional Status of Children with Cerebral Palsy. Clinical Nutrition ESPEN. Vol. 26, 2018, 27-34.

[12] Rahmat D, Mangunatmadja I, Tridjaja B, Tambunan T, Suradi R. Prevalence and Risk Factors for Epilepsy in Children with Spastic Cerebral Palsy. Paediatrica Indonesiana. Vol. 50, No. 1, 2010, pp. 11-7.

[13] Sellier E, Uldall P, Calado E, Sigurdardottir S, Torrioli MG, Platt MJ, dkk. Epilepsy and Cerebral Palsy: characteristics and trends in children born in 1976-1998. European Journal of Pediatric Neurology. Vol. 16, No. 1, 2012, pp. 48-55.

[14] Wibowo AR, Saputra DR. Prevalens dan Profil Klinis pada Anak Palsi Serebral Spastik dengan Epilepsi. Sari Pediatri. Vol. 14, No. 1, 2012, pp. 1-7.

[15] Gururaj AK, Sztriha L, Bner A, Eapen V. Epilepsy in Children with Cerebral Palsy. Seizure. Vol. 12, No. 2, 2003, pp. 110-4. 